\title{
Drug discrimination learning with naloxone: An assessment of the role of precipitated withdrawal
}

\author{
MARY A. KAUTZ, BETH GETER, SCOTT T. SMURTHWAITE, and ANTHONY L. RILEY \\ The American University, Washington, D.C.
}

\begin{abstract}
Recently, it has been reported that the opiate antagonist naloxone hydrochloride could serve as a discriminative cue in drug discrimination learning (DDL) within a conditioned taste aversion (CTA) design. Given that the animals were chronically exposed to saccharin and that naloxone has been shown to precipitate withdrawal in animals with such exposure, it was possible that the cue to which these animals attended was that of naloxone-precipitated withdrawal. To test this possibility, in the present study animals were chronically exposed to saccharin for 14 days prior to the pairing of saccharin with a naloxone injection in a procedure that paralleled the parameters of the DDL study within a CTA design. The present findings did not demonstrate a potentiation of a naloxone-induced aversion in animals chronically preexposed to saccharin (i.e., there was no evidence of naloxone-precipitated withdrawal). The failure of chronic saccharin exposure to potentiate a naloxone aversion in the present study, under the procedure that supported naloxone DDL, suggests that naloxone-precipitated withdrawal was not likely the discriminative cue in the previous study.
\end{abstract}

In a discussion of the differences between opiatedependent and -nondependent animals in using opiate antagonists as discriminative stimuli in a drug discrimination procedure, France and Woods (1988) noted that dependent animals likely use stimuli related to opiate abstinence as the discriminative cue, whereas actions on some undefined nonopioid system likely mediate the discrimination in nondependent animals.

The basis for the conclusion regarding the stimulus activity of opiate antagonists in dependent animals stems from the fact that such animals display clear signs of precipitated withdrawal when injected with the antagonist, effects that have been reported to serve as stimuli in both drug discrimination (see Stolerman, Rasul, \& Shine, 1989) and taste aversion (see Ternes, 1975) designs. The basis of the nonopioid nature of the antagonist stimulus in nondependent animals comes from a variety of sources (for a review, see France \& Woods, 1988). First, when opiate antagonists do serve as discriminative stimuli, generally they do so only at very high doses. Second, once a discrimination is acquired to the narcotic antagonist, other effective opiate antagonists do not always substitute. Third, the stimulus properties of opiate antagonists are not blocked by concurrent treatment with morphine. And finally, although acute pretreatment with morphine increases the sensitivity of naltrexone as a discriminative

This research was supported by a grant from the Mellon Foundation to Anthony L. Riley. Requests for reprints should be sent to Mary A. Kautz, Psychopharmacology Laboratory, Department of Psychology, The American University, Washington, DC 20016. stimulus, there is no change in sensitivity for other opiate antagonists.

Thus, there appears to be little support for the involvement of the opioid system in the stimulus properties of opiate antagonists in opiate-naive animals. Recently, however, Kautz, Geter, McBride, Mastropaolo, and Riley (1989) have suggested that this conclusion may be dependent in part on the specific design used in the assessment of discrimination learning with the antagonists. For example, in the assessment of naloxone drug discrimination learning within the taste aversion design (see Mastropaolo, Moskowitz, Dacanay, \& Riley, 1989), animals given an intraperitoneal (i.p.) injection of naloxone (1 or $3 \mathrm{mg} / \mathrm{kg}$ ) prior to a saccharin- $\mathrm{LiCl}$ pairing (and with its vehicle prior to saccharin alone) rapidly acquired the discrimination within three conditioning trials, decreasing the amount of saccharin consumed following the administration of naloxone and consuming saccharin following its vehicle. Furthermore, on subsequent generalization tests, the naloxone cue generalized to the opiate antagonist naltrexone while it failed to generalize to the agonist morphine. Given the aforementioned bases for the interpretation of the nonopioid mediated nature of narcotic antagonists in DDL, these data within the CTA design suggest that the discriminative stimulus properties of naloxone may be opiate-mediated.

Recently, Walker, Leavitt, and Mucha (1988) have reported data that may provide insight into how the stimulus properties of naloxone may be mediated at the opiate receptor. In examining whether chronic exposure to saccharin would potentiate the aversive property of naloxone, animals were given ad-lib access to saccharin for 14 
days prior to taste aversion conditioning in which a monosodium glutamate/sodium chloride mixture or a sodium saccharin/citric acid mixture was paired on three different occasions with a subcutaneous injection of naloxone $(0.09 \mathrm{mg} / \mathrm{kg})$. Animals given chronic exposure to saccharin developed a stronger CTA to the naloxone-paired flavor than animals chronically exposed to water. Walker et al. suggested that the potentiated aversion was a result of precipitated withdrawal. According to Walker and her colleagues, chronic saccharin exposure resulted in elevated endorphin levels and, in turn, dependence. Administration of naloxone presumably precipitated withdrawal in these subjects, an effect sufficient to condition an aversion to the mixture presented immediately prior to the naloxone injection. This possibility is supported by the fact that chronic exposure to saccharin increases endorphin levels (see Dum, Gramsch, \& Herz, 1983) and that naloxoneprecipitated withdrawal conditions taste aversions in rats (see Parker \& Radow, 1974).

In the prior assessment of DDL with naloxone, on every 4th day, animals were given an i.p. injection of naloxone followed by a saccharin- $\mathrm{LiCl}$ pairing (see Kautz et al., 1989). On intervening days, the animals received an equivolume injection of distilled water followed by access to the same saccharin solution. This daily 20 -min access to saccharin served as the only source of fluids throughout the study. Thus, it is possible that, due to chronic saccharin exposure, an opioid dependence was created by the subsequent increased levels of endogenous opiates and naloxone's cuing effect was that of precipitated withdrawal. This possibility is supported by the fact that drug discrimination learning has been obtained with naloxoneprecipitated withdrawal in morphine-dependent animals (see Weissman, 1978). In the present study, this possibility was examined by assessing the effect of chronic saccharin exposure on naloxone's ability to condition a taste aversion (an index of precipitated withdrawal) under conditions that parallel those used in the Kautz et al. (1989) report.

\section{METHOD}

\section{Subjects and Apparatus}

The subjects were 24 experimentally naive, female rats of Long-Evans descent, approximately 120 days of age at the beginning of the experiment. The subjects were housed in individual wire-mesh cages and were maintained on a 12:12-h light:dark cycle at an ambient temperature of $23^{\circ} \mathrm{C}$ for the duration of the experiment.

\section{Procedure}

Phase 1: Preexposure. Following 3 days of ad-lib access to water, subjects were matched on water consumption and assigned to four groups ( $\mathrm{n}=6$ per group). On the following day (Day 1), a novel saccharin solution $(0.1 \% \mathrm{w} / \mathrm{v}$ sodium saccharin, Fisher purified) replaced water for two of the groups (i.e., Groups SW and SN), while the two remaining groups (Groups WW and WN) continued to receive water. The animals were given ad-lib access to their respective solutions for 14 consecutive days.

Phase 2: Habituation. On Days 15-17, all subjects were again given ad-lib access to water. All water bottles were then removed from the cages for $24 \mathrm{~h}$, after which all subjects were given 20-min access to water once per day for 3 consecutive days (Days 19-21).

Phase 3: Saccharin/naloxone pairings. On Day 22, all subjects received 20 -min access to the saccharin solution. Fifteen minutes fol- lowing saccharin consumption, the subjects in Groups SN and WN were given an i.p. injection of $1 \mathrm{mg} / \mathrm{kg}$ naloxone hydrochloride (DuPont Pharmaceuticals, Inc.). The subjects in Groups SW and WW were given an equivolume injection of distilled water. On the following 3 days, all subjects were given 20 -min access to water. No injections were administered following this water access. This alternating procedure of conditioning/water recovery was repeated for six complete cycles. Following the final 3 recovery days of Phase 3 , the subjects were given 20 -min access to both saccharin and water in a two-bottle test of the aversion to saccharin.

\section{RESULTS}

All statements regarding statistical significance on conditioning and recovery days are based on a three-way analysis of variance with repeated measures on one factor. Statistical significance reported during the two-bottle test is based on a paired $t$ test. All significance levels are set at $p<.05$.

\section{Saccharin/Naloxone Pairings}

Figure 1 presents the mean absolute consumption of saccharin (on conditioning days) and of water (on recovery days) for subjects preexposed to water (i.e., Groups WW and WN: top panel) and to saccharin (i.e., Groups SW and SN: bottom panel) throughout the conditioning/ recovery cycles.

Groups WW and WN. Animals in Groups WW and WN consumed a mean of approximately 11.0 and $10.5 \mathrm{ml}$

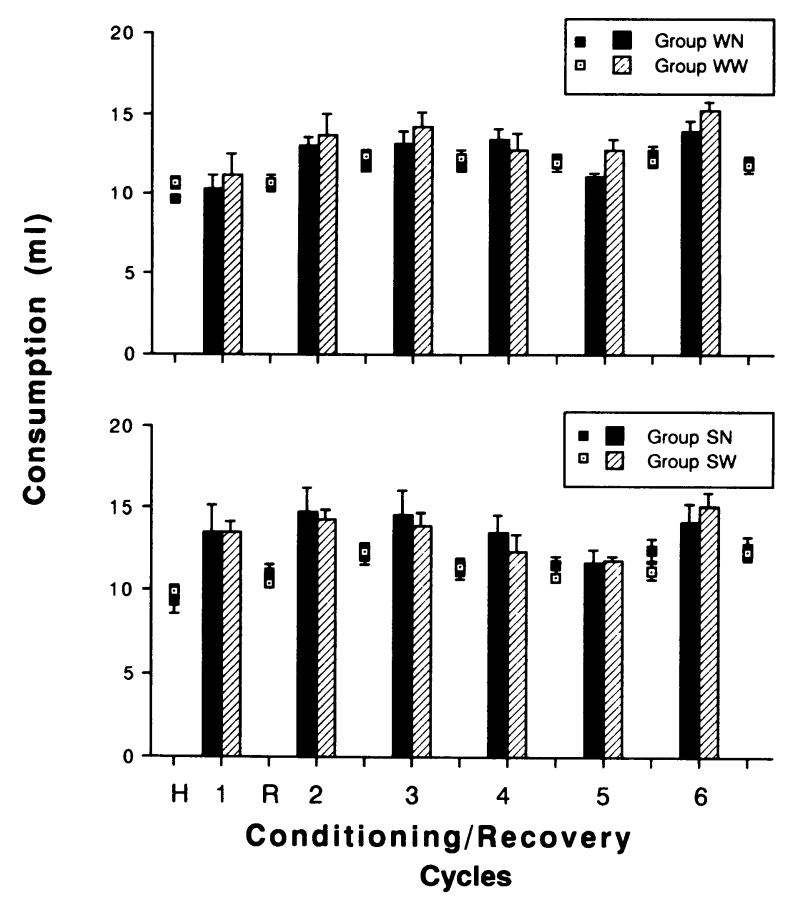

Figure 1. Mean absolute saccharin consumption for subjects in Groups WN and WW (upper panel) and Groups SN and SW (lower panel) over repeated conditioning days (1-6). H refers to the mean consumption during the 3 days of water habituation prior to the first naloxone/saccharin pairing. $\mathbf{R}$ refers to the mean water consumption over the three recovery days between conditioning days. Bars represent SEM. 
of saccharin, respectively, on the first conditioning trial. Saccharin consumption increased slightly and remained high throughout conditioning, with subjects drinking approximately 15.0 and $14.0 \mathrm{ml}$ of saccharin (Groups WW and $\mathrm{WN}$, respectively) on the final conditioning day preceding the two-bottle test. There were no significant differences between groups on any of the conditioning trials or on the intervening recovery days.

Groups SW and SN. Animals in Groups SW and SN consumed approximately $13.5 \mathrm{ml}$ of saccharin on the first conditioning trial. Consumption for both groups remained high throughout conditioning, with subjects in Groups SW and SN consuming approximately 15.0 and $14.0 \mathrm{ml}$ of saccharin, respectively, on the final conditioning day preceding the two-bottle test. There were no significant differences between groups on any of the conditioning trials or on the intervening recovery days.

\section{Two-Bottle Test}

Figure 2 presents mean absolute consumption when both saccharin and water were available for subjects preexposed to water (i.e., Groups WW and WN: top panel) and to saccharin (i.e., Groups SW and SN: bottom panel) during the two-bottle test.

Groups WW and WN. The subjects in Group WW drank significantly more saccharin than water $[t(5)=$ 3.09] during the two-bottle test. Although the subjects in Group WN showed a tendency to drink more saccharin than water, this difference was not significant. There were no significant differences between groups in the amount of either saccharin or water consumed on this test.

Groups SW and SN. The subjects in both groups (SW and $\mathrm{SN}$ ) drank significantly more saccharin than water

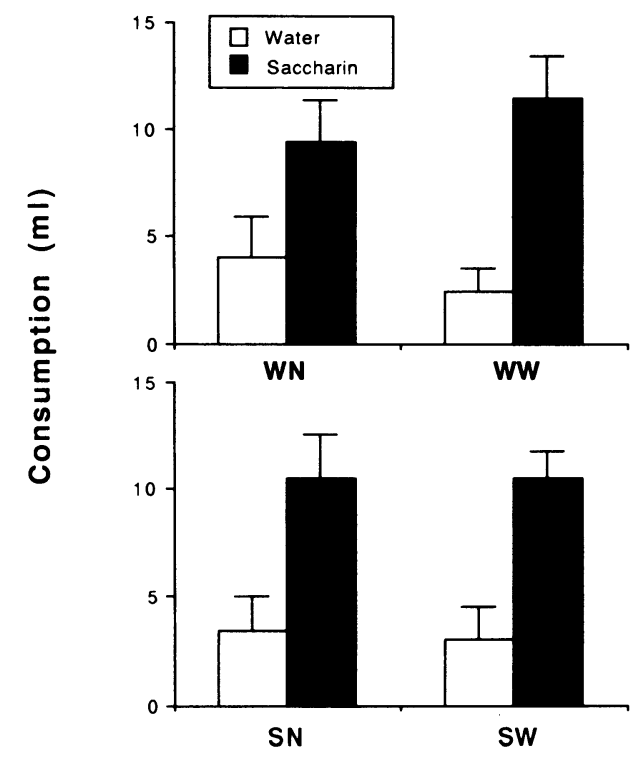

Figure 2. Mean absolute water and saccharin consumption for subjects in Groups WN and WW (upper panel) and Groups SN and SW (lower panel) during the two-bottle test. Bars represent SEM. $[t(5)=2.05$ and $t(5)=2.69$, respectively $]$ during the two-bottle test. There were no significant differences between groups in the amount of either saccharin or water consumed on this test.

\section{DISCUSSION}

Chronic exposure to saccharin prior to a pairing of saccharin and naloxone did not potentiate a naloxone-induced taste aversion. As evidenced in both the one-bottle and the two-bottle tests, animals preexposed to saccharin and administered an injection of naloxone did not consume less saccharin than water-preexposed, naloxone-injected subjects (i.e., the control subjects).

The specific parameters of the present study, under which a potentiated naloxone-induced aversion was not found, were chosen to parallel those used by Kautz et al. (1989) in their demonstration of naloxone DDL in a CTA design. Because morphine-naive animals rapidly acquired the naloxone discrimination at low doses, and because another mu antagonist (i.e., naltrexone) subsequently substituted for the naloxone cue, it was concluded that the discriminative properties of naloxone are mediated at the opiate receptor (see above). Given that animals in the Kautz et al. report received chronic exposure to saccharin and that naloxone has been reported to precipitate withdrawal in animals chronically preexposed to saccharin (Walker et al., 1988), one possible mechanism underlying the opioid mediation of the stimulus properties of naloxone was that of naloxone-precipitated withdrawal. That the present findings did not demonstrate a potentiation of a naloxone-induced aversion in animals chronically preexposed to saccharin (i.e., there was no evidence of naloxone-precipitated withdrawal) under the procedure that supported naloxone DDL suggests that naloxone-precipitated withdrawal was not likely the basis of the naloxone discrimination reported by Kautz et al. (1989). The exact mechanism underlying the opioid mediation remains unknown. That chronic saccharin exposure did not potentiate a naloxone aversion in the present study is somewhat surprising, in light of other evidence demonstrating the effect of chronic saccharin exposure on opiate sensitivity (see Walker et al., 1988). The basis for the failure of the present study to demonstrate a naloxone-potentiated aversion to saccharin may be a function of the specific parameters used in this study. The present study was designed to examine the effect of chronic saccharin exposure on a naloxone-induced aversion, using the general parameters of a prior demonstration of a naloxone discrimination. Specifically, individually housed animals, preexposed to the same solution to which they were conditioned, were administered an i.p. injection of naloxone paired with 20 -min access to saccharin. A subsequent two-bottle test of taste preference was also limited to $20 \mathrm{~min}$. Although each of these procedural variables has been reported to support CTA learning, each also notably weakens a CTA even when a taste is paired with a classic emetic such as $\mathrm{LiCl}$ (for a review, see Riley \& Tuck, 1985).

\section{REFERENCES}

Dum, J., Gramsch, C., \& Herz, A. (1983). Activation of hypothalamic b-endorphin pools by reward induced by highly palatable food. Pharmacology, Biochemistry \& Behavior, 18, 443-447.

France, C. P., \& WoOdS, J. H. (1988). Acute supersensitivity to the discriminative stimulus effects of naltrexone in pigeons. Journal of Pharmacology \& Experimental Therapeutics, 244, 599-605.

Kautz, M. A., Geter, B., McBride, S. A., Mastropaolo, J. P., \& Riley, A. L. (1989). Naloxone as a stimulus for drug discrimination learning. Drug Development Research, 16, 317-326.

Mastropaolo, J. P., Moskowitz, K. A., Dacanay, R. J., \& RiLeY, A. L. (1989). Conditioned taste aversions as a behavioral baseline for drug discrimination learning: An assessment with phencyclidine. Pharmacology, Biochemistry \& Behavior, 32, 1-8.

PARKer, L., \& RADOW, B. (1974). Morphine-like physical dependence: A pharmacologic method for drug assessment using the rat. Pharmacology, Biochemistry \& Behavior, 2, 613-618. 
Riley, A. L., \& TUCK, D. L. (1985). Conditioned taste aversions: A behavioral index of toxicity. Annals of the New York Academy of Sciences, 443, 272-292.

Stolerman, I. P., Rasul, F., \& Shine, P. J. (1989). Trends in drug discrimination research analysed with a cross-indexed bibliography, 1984-1987. Psychopharmacology, 98, 1-19.

TERNES, J. W. (1975). Conditioned aversion to morphine with naloxone. Bulletin of the Psychonomic Society, 5, 292-294.

Walker, M. J. K., LeavitT, B., \& Mucha, R. F. (1988). Saccharin exposure increases the potency and aversive property of naloxone in drug-naive rats. Life Sciences, 43, 1305-1311.

WeISSMAN, A. (1978). The discriminability of naloxone in rats depends on concomitant morphine treatment. In F. C. Colpaert \& J. A. Rosecrans (Eds.), Stimulus properties of drugs: Ten years of progress (pp. 209-214). Amsterdam: Elsevier/North-Holland Biomedical Press.

(Manuscript received June 25, 1990.) 